\title{
DEFORMATION AND STRENGTH OF GEOGRID-REINFORCED GRANULAR SOIL AT PLANE STRAIN CONDITIONS
}

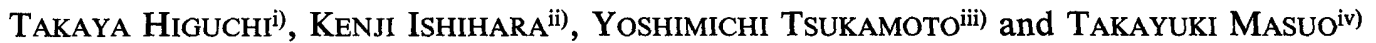

\begin{abstract}
This paper reports deformation and strength characteristics for a geogrid-reinforced granular soil on a large-scale plane strain compression apparatus. The influence of intensity and types of geogrid reinforcement is specifically discussed. It was found that as more reinforcement layers are used, the strength of the reinforced soil increased. In cases where reinforcement is most intensely used, the reinforcement layers in the samples were eventually subject to breakage due to plane strain compression and the reinforced soil failed. In cases where reinforcement is less intensely used, the reinforced soil reached failure without any sign of reinforcement breakage. It was also found that types of reinforcement have a significant influence on the lateral deformation of the reinforced soil, where stiffer reinforcement provides more constraints on lateral deformation of the reinforced soil. It can be superceded, however, by the influence of reinforcement intensity. The small strain measurement by means of LDT observed that the stiffness of non-reinforced soil begins to decrease more rapidly at a strain level of $0.05 \sim 0.15 \%$, compared to the reinforced soil. The experimental results also indicate that the relationship between the apparent angle of internal friction and the geometry of the structure of the reinforced granular soil seems to exist for the geogrid reinforcement used in the tests reported in this paper.
\end{abstract}

Key words: deformation, geogrid, plane strain, reinforced soil, shear strength (IGC: D6/E5)

\section{INTRODUCTION}

Earth reinforcement practice has been recognized as a useful means to reinforce earthwork around the world. In particular, there are a wide variety of geogrids available to geotechnical engineers, (Akagi et al., 1994 and others). Deformation and strength characteristics of geogrid-reinforced soil have been studied until now, using a triaxial compression apparatus, (Yang 1972; Kutara et al., 1987; Nishimura et al., 1988; Kutara et al., 1991; Moroto 1992 and others), and plane strain compression apparatus, (Hamada et al., 1983; Japanese Society of Soil Mech. Found. Eng. 1988 and others). Pullout tests have also been extensively made, (Bouazza and Wei 1992; Cancelli et al., 1992; Mitachi et al., 1992; Ochiai et al., 1992 and others).

In the study described herein, large-scale plane strain compression tests were carried out, and deformation and strength characteristics for geogrid-reinforced granular soil under plane strain compression were investigated.

\section{EXPERIMENTAL DETAILS}

The test series reported herein used dry Toyoura sand, and two different types of geogrid materials. Type-A geogrid reinforcement is made of polyacrylate sheet and Type- $B$ is made of vinylon sheet. Table 1 shows the material properties of the Toyoura sand, and Table 2 shows the physical properties of the two geogrid reinforcements. A large-scale plane strain compression apparatus was used, which can accommodate soil samples of $D=214 \mathrm{~mm}$ in depth, $L=244 \mathrm{~mm}$ in width and $H=570$ $\mathrm{mm}$ in height, as shown in Fig. 1. The axis representing the width of the samples is normal to the plane strain condition. It is clear that testing at plane strain conditions is advantageous for exploring the inborn uniaxial or biaxial characteristics of geogrid-reinforced soil. The stresses acting on the soil sample comprise $\sigma_{1}, \sigma_{2}$ and $\sigma_{3}$, in which $\sigma_{1}$ and $\sigma_{3}$ can be controlled in the tests. $\sigma_{1}$ is the vertical stress applied through the axial rod from the top of the sample. $\sigma_{3}$ is the horizontal stress which confines the samples through a rubber membrane. $\sigma_{2}$ is the horizontal

i) Graduate Student, Department of Civil Engineering, Science University of Tokyo.

ii) Professor, ditto.

iii) Research Associate, ditto.

iv) Taiyo Kogyo Corporation, Civil Engineering Products Division.

Manuscript was received for review on June 5, 1996.

Written discussions on this note should be submitted before October 1, 1998 to the Japanese Geotechnical Society, Sugayama Bldg., 4F, Kanda Awaji-cho, 2-23, Chiyoda-ku, Tokyo 101-0063, Japan. Upon request the closing date may be extended one month. 
Table 1. Material properties of Toyoura sand

Specific gravity $G_{s}$

Maximum grain size for sample $D_{\max }(\mathrm{mm})$

Maximum grain size in smallest $50 \%$ of sample $D_{50}(\mathrm{~mm})$

Coefficient of uniformity $U_{c}$

Coefficient of curvature $U_{c}^{\prime}$

Maximum void ratio $e_{\max }$

Minimum void ratio $e_{\min }$
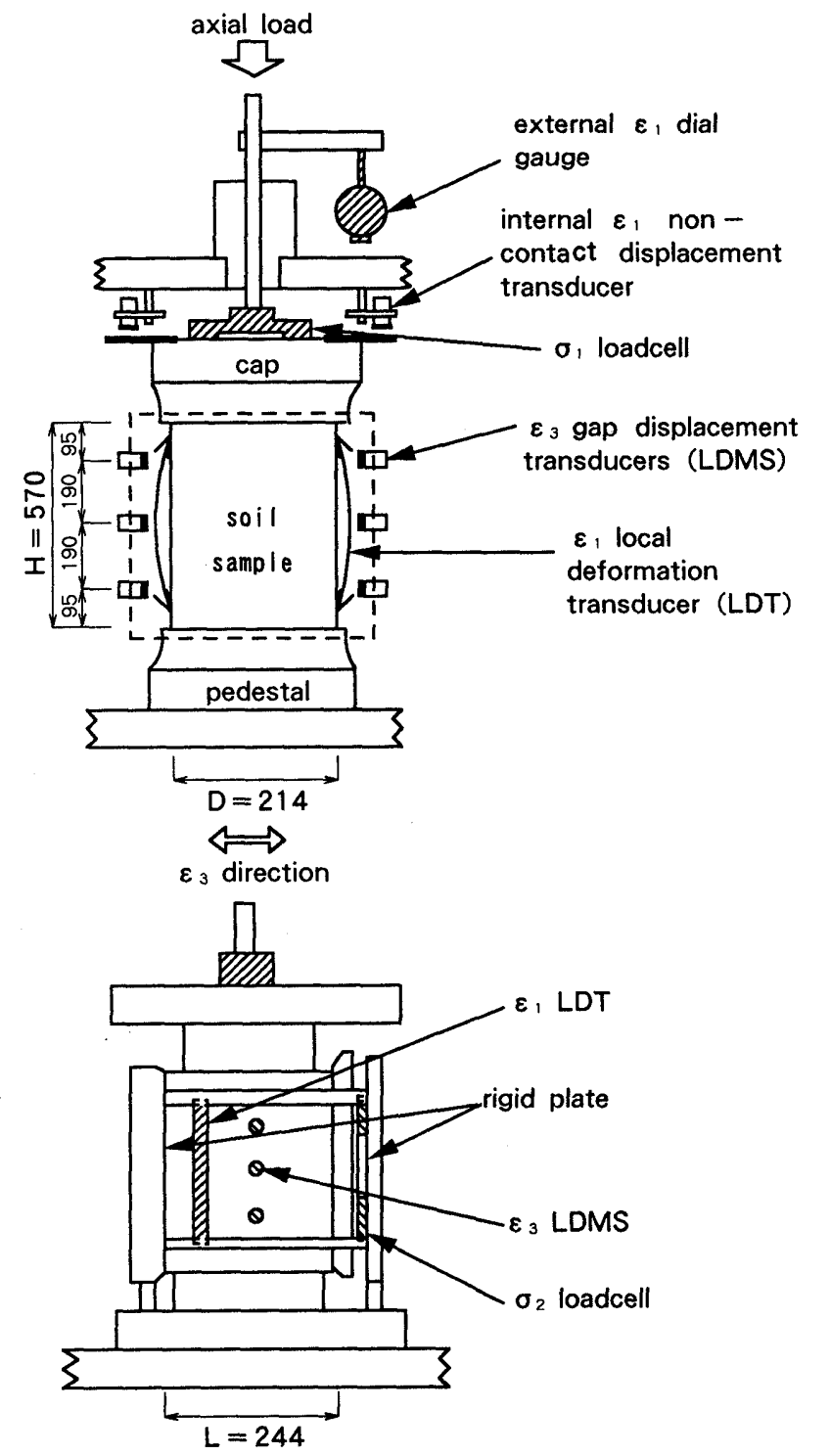

.634

0.425

0.180

1.4

0.9

0.977

0.605
Table 2. Physical properties of geogrids

\begin{tabular}{l|c|c}
\hline Type & Type-A & Type-B \\
\hline Material & vynilon & polyarylate \\
Apertures $(\mathrm{mm})$ & $19 \times 20$ & $20 \times 17$ \\
Tensile strength at failure $(\mathrm{kN} / \mathrm{m})$ & 69.6 & 61.7 \\
Tensile strain at failure $(\%)$ & 11.9 & 7.6 \\
Tensile stiffness $(\mathrm{kN} / \mathrm{m})$ & $5.85 \times 10^{2}$ & $8.12 \times 10^{2}$ \\
\hline
\end{tabular}

\section{not to scale dimensions in $\mathrm{mm}$}

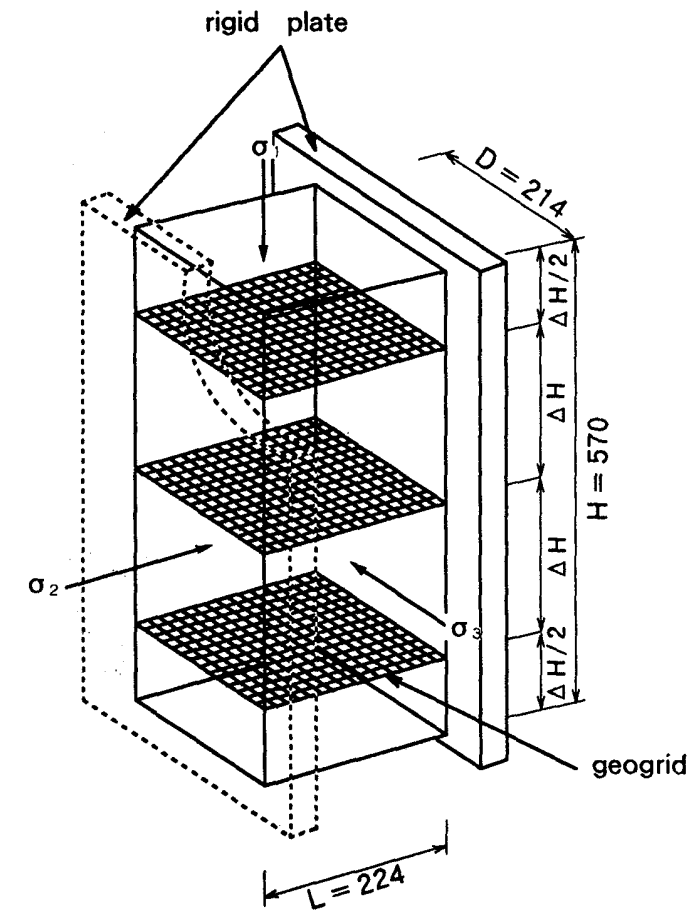

$\left[\begin{array}{l}\text { Diagram of test samples } \\ \text { for } 3 \text { reinforcement layers }\end{array}\right]$ stress acting to the rigid acrylic plates which confine the sides of the samples and generate the plane strain conditions in the samples, and measures in and out of plane stresses. The vertical displacement of the samples was measured with external and internal dial gauges, and local deformation transducers (LDT), attached to the $\sigma_{2}$ sides of the samples. The horizontal displacement of the samples was measured at three different positions on the $\sigma_{3}$ sides of the samples, using gap displacement transducers (lateral deformation measuring system, i.e.

\section{LDMS).}

An air pluviation method was used for the preparation of the soil samples, and the relative density $D_{r}$ was $90 \%$. Several layers of the geogrid reinforcement described above were placed horizontally with equal spacing in the soil samples. A total of seven test series were conducted with different soil-reinforcement configurations. One test was conducted without geogrid reinforcement, while the other tests were conducted with 3, 6 or 11 layers for each geogrid reinforcement. After the geogrid-reinforced soil 
samples were prepared, the vertical stress and horizontal stress were increased to provide $\sigma_{3}=19.6 \mathrm{kPa}$ and $\sigma_{3} /$ $\sigma_{1}=0.4$, and the samples were anisotropically consolidated. This procedure was necessary to test the geogridreinforced soil, because the geogrid reinforcement in the samples needs to be tensile-strained prior to axial compression and it also conforms to field stress states. The vertical stress was then gradually increased at a constant strain rate of $0.125 \% / \mathrm{min}$ until the samples "failed".

\section{TEST RESULTS}

The influence of the intensity of reinforcement layers in the samples on deformation and strength characteristics of geogrid-reinforced soil is discussed below. Figures 2(a) and 3(a) show the test results for the stress ratio $\sigma_{1} /$ $\sigma_{3}$-axial strain $\varepsilon_{1}$ curves for Type-A and Type-B reinforcement, respectively. It can be clearly seen that the stress ratios for all tests increase with strain and decrease after experiencing peaks. The stress ratio at peak increases and also the axial strain at peak increases with an increase in the geogrid reinforcement layers in the samples. The close observation of the samples after the tests provided a good insight into two different types of possible failure modes for geogrid-reinforced soil. In cases where 11 layers of either Type-A or Type-B reinforcement were used, the geogrid-reinforcement layers were subject to breakage along the local soil failure planes. In cases where 3 or 6 layers of reinforcement were used, however the soil samples collapsed without any breakage of the reinforcement itself. This difference in the failure modes of geogrid rein-

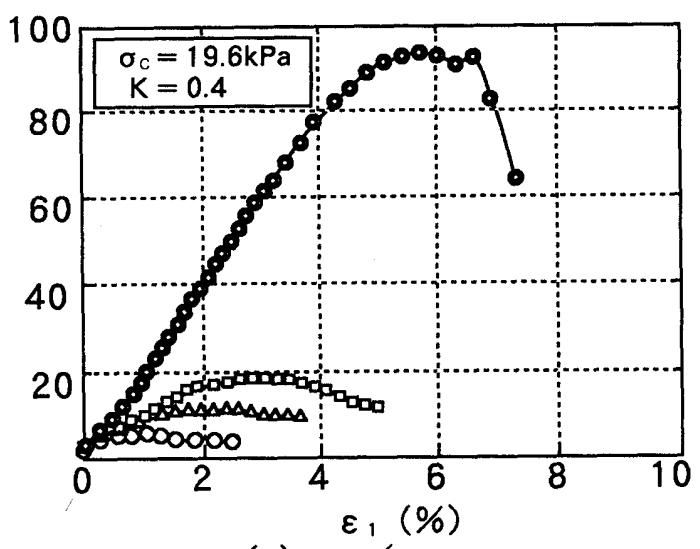

(a) $\boldsymbol{\sigma}_{1} / \boldsymbol{\sigma}_{3}-\varepsilon_{1}$

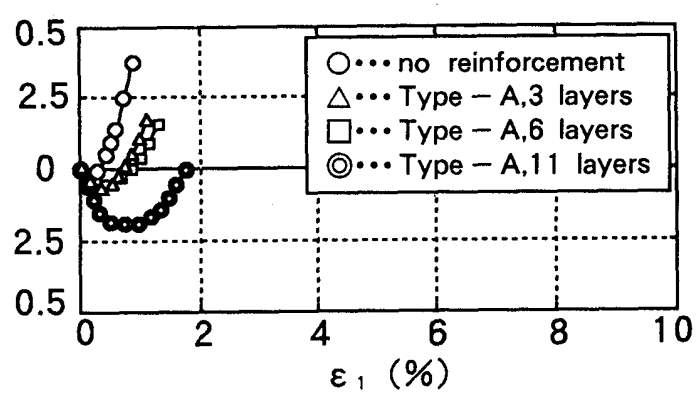

(b) $\varepsilon_{v}-\varepsilon_{1}$

Fig. 2. Test results on Type-A reinforcement forcement can be explained as follows: Due to axial compression, the samples bulge and lateral deformation of the samples occurs, which coincides with the direction of the geogrid reinforcement. The geogrid reinforcement is therefore subjected to tensile strain and tensile stress is induced along the reinforcement. The increase in the lateral tensile stress along the reinforcement may be considered to effectively contribute to the apparent increase in the lateral stress $\Delta \sigma_{3}$, leading to an increase in the strength of the reinforced samples compared to the non-reinforced sample. In cases where reinforcement is most intensely used therefore with 11 geogrid layers, the apparent increase in the lateral stress $\Delta \sigma_{3}$ occurred excessively, and the geogrid reinforcement may have been subjected to a tensile stress greater than the tensile strength of the geogrid reinforcement itself. In cases where 3 or 6 layers of reinforcement were used, the samples reached the soil shear strength before the tensile stress along the reinforcement, and $\Delta \sigma_{3}$ was equal to the tensile strength of the reinforcement. In addition, it should be noted in Figs. 2(a) and 3(a) that the stress ratios for the tests with 3 or 6 layers of the reinforcement gradually decreased after peaks, however, the tests with 11 layers of the reinforcement which experienced breakage suffered rapid reductions of the stress ratios after peaks. Less intensely reinforced soil therefore seems to show more ductile behaviour after peaks.

Figures 3(a) and 3(b) show the test results for volumetric strain $\varepsilon_{V}$-axial strain $\varepsilon_{1}$ curves for Type-A and Type-B reinforcement, respectively. Here, the volumetric strain

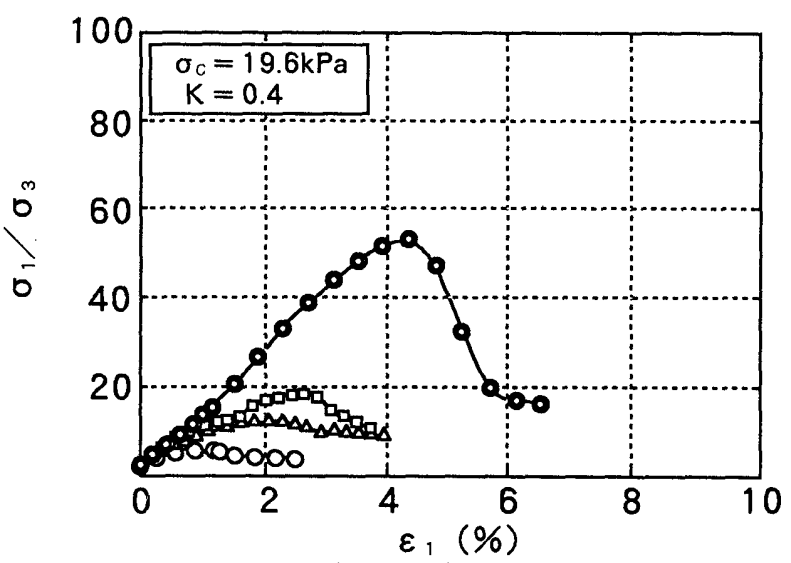

(a) $\sigma_{1} / \sigma_{3}-\varepsilon_{1}$

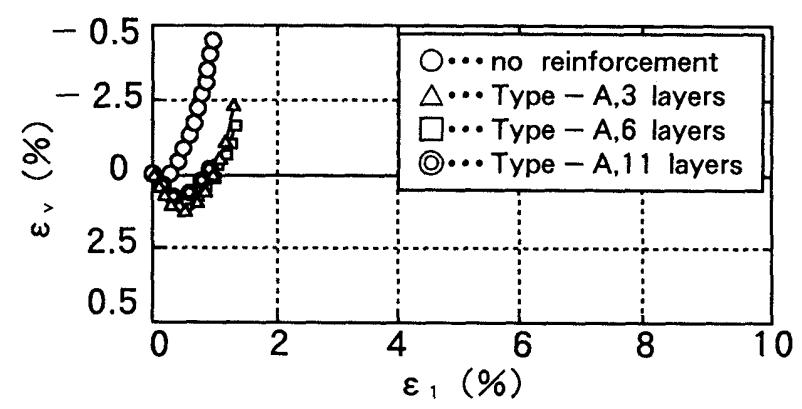

(b) $\varepsilon_{v}-\varepsilon_{1}$

Fig. 3. Test results on Type-B reinforcement 
is defined as $\varepsilon_{V}=\varepsilon_{1}+\varepsilon_{3}$ and the compressive strain is assumed positive. It can be clearly seen that the non-reinforced sample is first compressed and then begins to dilate at an axial strain of $0.1 \%$. The reinforced samples never dilate however until the axial strain of $0.4 \sim 0.8 \%$ is achieved. It is evident that the confinement and interaction of the reinforcement to the surrounding soil may play some role here. In Type-A reinforcement, the compressibility of the samples consistently increases with an increase in the reinforcement layers. In Type-B reinforcement, there is no major difference in the compressibility of the samples with respect to the intensity of the reinforcement in the samples. The difference in the physical properties of the reinforcement therefore also seems to be relevant.

The influence of types of geogrid reinforcement is quite complex and is discussed below. Figures 4,5 and 6 show the $\sigma_{1} / \sigma_{3}-\varepsilon_{1}$ curves and $\varepsilon_{V}-\varepsilon_{1}$ curves for 3,6 and 11 layers of two reinforcement, respectively. In the tests with 3 or 6 layers of the reinforcement, there is no distinct difference in the peak stress ratios, as shown in Figs. 4(a) and 5(a). There is a marked difference in the deformation characteristics of the $\varepsilon_{V}-\varepsilon_{1}$ curves, however where less stiff Type-A reinforcement shows less compressibility than Type-B reinforcement, as shown in Figs. 4(b) and 5 (b). In the tests with 11 layers of the reinforcement which experienced breakage, there is a significant difference in the peak stress ratios where Type-A reinforcement produces a higher peak stress ratio than Type-B reinforcement, as shown in Fig. 6(a). The $\varepsilon_{V} \varepsilon_{1}$ curves in

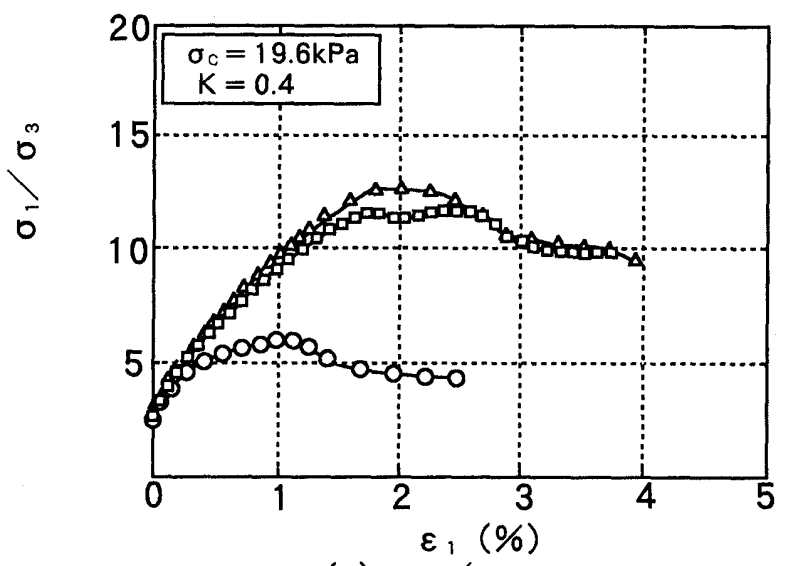

(a) $\sigma_{1} / \sigma_{3}-\varepsilon_{1}$

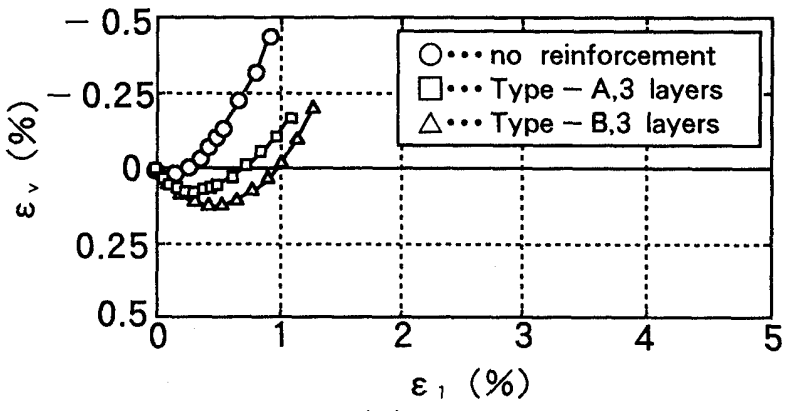

(b) $\varepsilon_{v}-\varepsilon_{1}$

Fig. 4. Test results on 3 reinforcement layers
Fig. 6(b) however become opposite compared to Figs. 4(b) and 5(b). When one has another look at lateral strain $\varepsilon_{3}$, it is clearly seen that lateral deformation of the

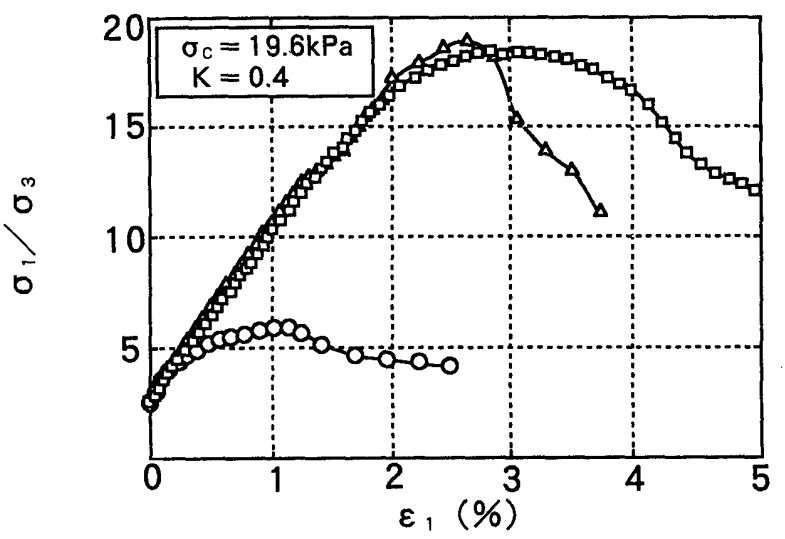

(a) $\sigma_{1} / \sigma_{3}-\varepsilon_{1}$

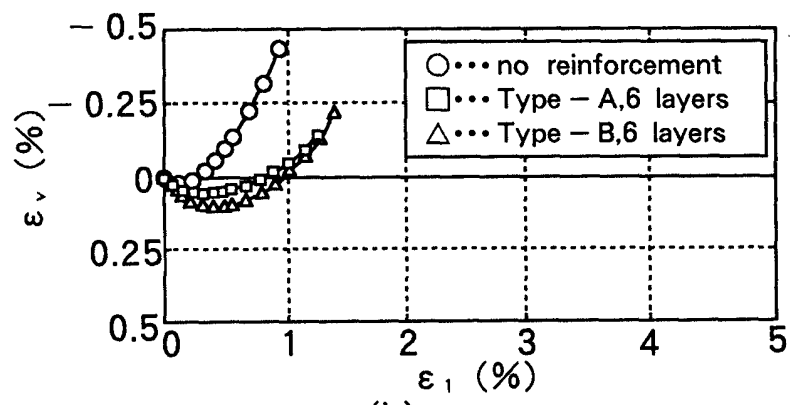

(b) $\varepsilon_{v}-\varepsilon_{1}$

Fig. 5. Test results on 6 reinforcement layers

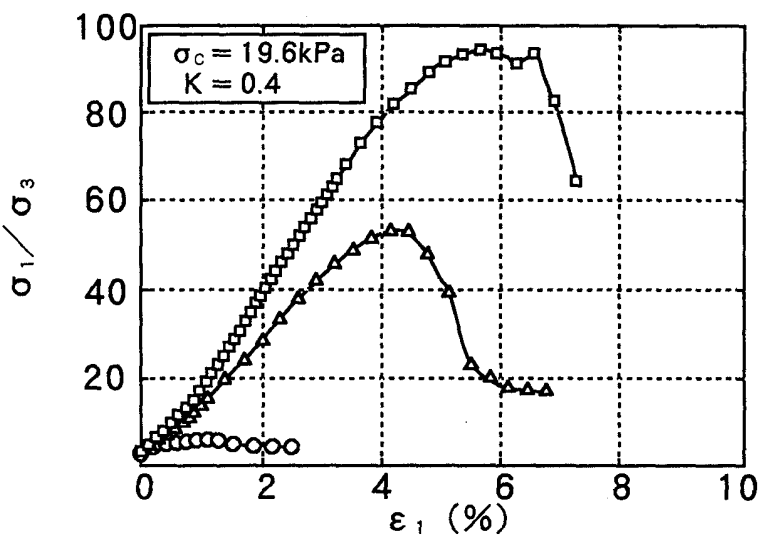

(a) $\sigma_{1} / \sigma_{3}-\varepsilon_{1}$

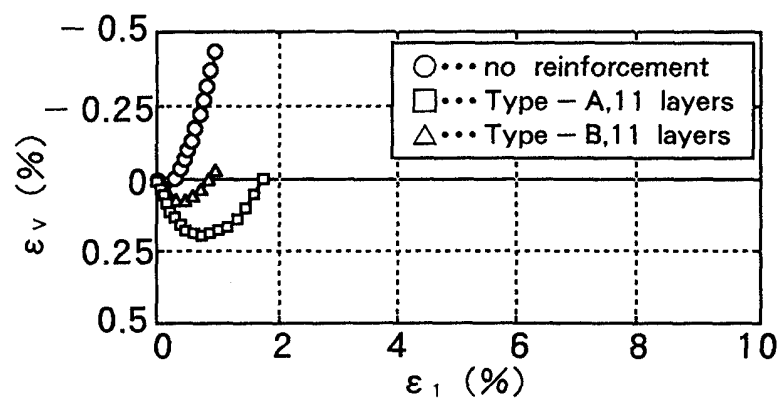

(b) $\varepsilon_{v}-\varepsilon_{1}$

Fig. 6. Test results on 11 reinforcement layers 
reinforced soil becomes more constrained by stiffer reinforcement in cases of 3 or 6 reinforcement layers, as shown in Fig. 7. It is also shown in Fig. 7 that 11 layers of reinforcement produce a smaller lateral deformation than 3 or 6 layers of reinforcement. Type-A reinforcement however provides more constraint on lateral deformation than Type-B reinforcement, which is opposite to the observation made on 3 or 6 layers of reinforcement. It was found therefore that the influence of intensity and types of reinforcement seems to be definitely related to each other. It should be noted that these differences arise due to which failure mode comes first; failures of the reinforced soil due to shear strength of the soil or in association with breakage of reinforcement.

Small strain measurement was made using displacement transducers known as LDT. Figure 8 shows behaviour of the deviatoric stress, $\sigma_{1}-\sigma_{3}$, against axial strain $\varepsilon_{1}$, and Fig. 9 indicates the behaviour of the secant shear

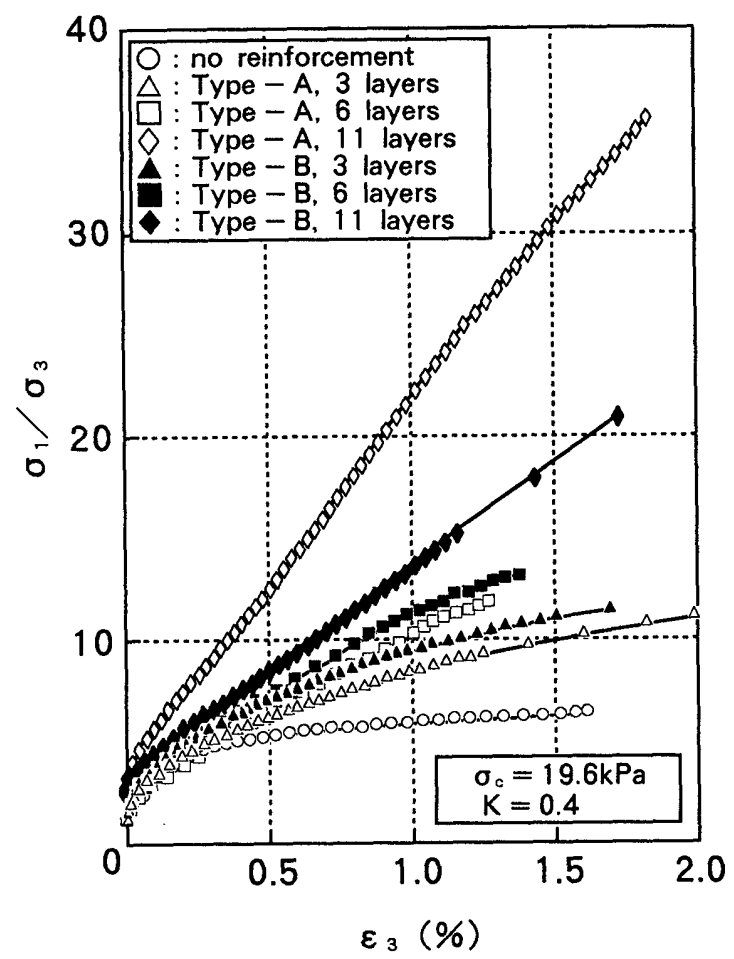

Fig. 7. $\sigma_{1} / \sigma_{3}-\varepsilon_{3}$ curves

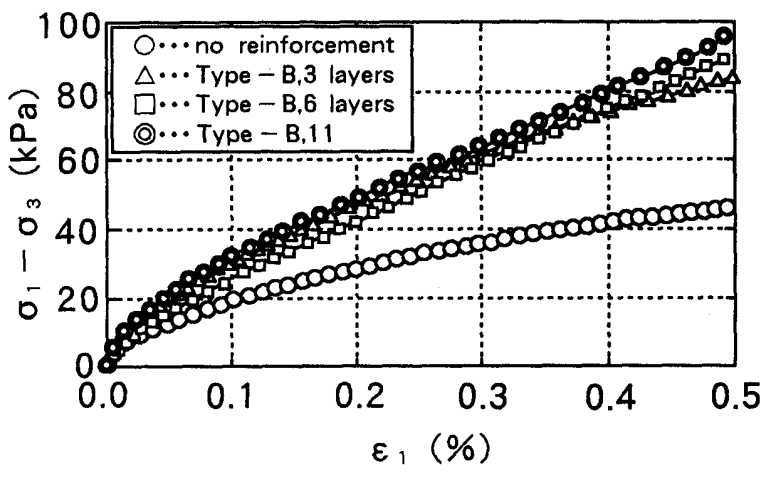

Fig. 8. LDT test results on Type-B reinforcement

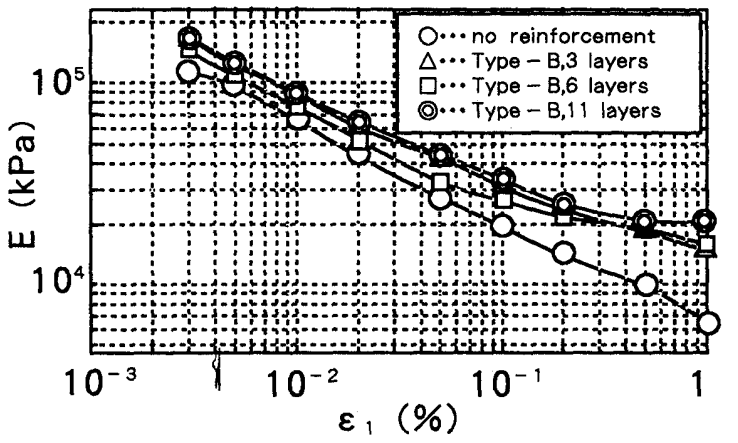

Fig. 9. $E-\varepsilon_{1}(\%)$ relationship

modulus $E$ against axial strain $\varepsilon_{1}$ at a range of $0 \sim 0.1 \%$, where $E$ is defined as $E=\left(\sigma_{1}-\sigma_{3}\right) / \varepsilon_{1}(\mathrm{kPa})$. It can be seen that the stiffness of the non-reinforced soil begins to decrease more rapidly at a strain level of $0.05 \sim 0.1 \%$, compared to the reinforced soil. There is no major difference in the secant stiffness of the reinforced soil structures however with different reinforcement intensities.

\section{IMPLICATION TO DESIGN}

Figure 10 shows the peak stress ratios $\left(\sigma_{1}-\sigma_{3}\right)_{f}$ against the $D / \Delta H$ ratio, where $D$ is the depth of the sample and $\Delta H$ is the spacing between the reinforcement layers in the samples. The peak stress ratio of the non-reinforced sample is plotted at $D / \Delta H=0$. It can be seen that the peak stress ratio gradually increases as the $D / \Delta H$ ratio increases, and there is a sudden increase of the peak stress ratio for the test of $D / \Delta H>4$, where the geogrid reinforcement was torn off. Figure 11 shows the apparent angle of internal friction for the samples $\phi_{f}$ against the $D / \Delta H$ ratio, where $\phi_{f}$ is calculated from the peak stress ratio as follows;

$$
\phi_{f}=\sin ^{-1} \frac{\left(\sigma_{1} / \sigma_{3}\right)_{f}-1}{\left(\sigma_{1} / \sigma_{3}\right)_{f}+1} .
$$

From the test results in Fig. 11, there seems to be a linear relationship between the apparent angle of internal friction $\phi_{f}$ and the $D / \Delta H$ ratio;

$$
\phi_{f}=\alpha+\beta(D / \Delta H) \text {, }
$$

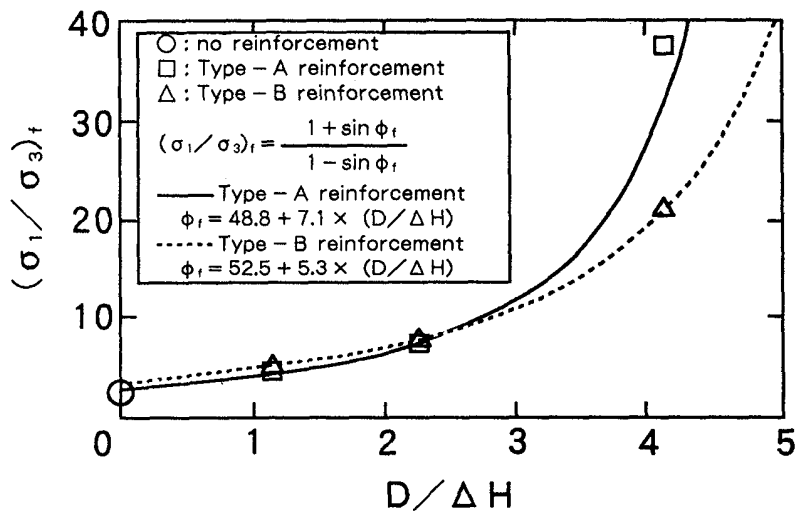

Fig. 10. $\left(\sigma_{1} / \sigma_{3}\right)_{f}-D / \Delta H$ relationships 


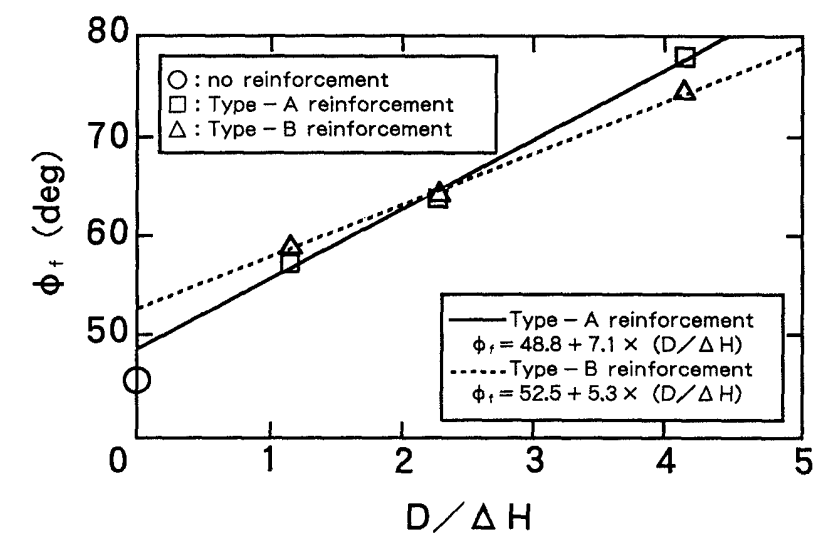

Fig. 11. $\phi_{f}-D / \Delta H$ relationships

where $\alpha$ and $\beta$ are constants which depend on the type of geogrid reinforcement. The relationships between the peak stress ratios $\left(\sigma_{1}-\sigma_{3}\right)_{f}$ and $D / \Delta H$ ratio can be obtained by manipulating Eqs. (1) and (2), and are also plotted in Fig. 10. This proposed relationship in Fig. $10 \mathrm{im}-$ plies that there is a sudden increase in the peak stress ratio at around $D / \Delta H=3$, suggesting that the use of more than or less than 7 or 8 layers of the reinforcement in the samples is the boundary which separates the above-described two failure modes of whether the reinforced soil samples reach collapse due to shear strength of soil or in association with breakage of reinforcement. The discussions presented above are only limited to the experimental results reported herein, in which the tests were conducted only on one size of test samples. It should be noted therefore that the use of the apparent angles of internal friction derived here require careful note of the scale effects of the samples, the discrepancy between model and prototype and also the actual conditions in the field.

\section{CONCLUSIONS}

This paper reported the results of plane strain compression tests on geogrid-reinforced dense sand. The influence of intensity and types of reinforcement on the deformation and strength characteristics of the reinforced granular soil was studied specifically. The influence of intensity of reinforcement was characterized by the two failure modes, in which less intensely reinforced soil fails due to shear strength of soil and intensely reinforced soil collapsed in association with breakage of reinforcement. It was also found that as the intensity of reinforcement increases, the reinforcement tension becomes more prominent and constrains lateral deformation more effectively and even breakage of the reinforcement was observed. The influence of types of reinforcement is complex, and can be superceded by the influence of reinforcement intensity. It can be characterized by the stiffness of reinforcement. It was found that the types of reinforcement have a significant influence on lateral deformation of the reinforced soil. Small strain measure- ment was made using LDT, and it was shown that the stiffness of non-reinforced soil begins to decrease more rapidly at a strain level of $0.05 \sim 0.1 \%$, compared to the reinforced soil. The experimental results showed that the relationship between the apparent angle of internal friction of the reinforced soil and the depth to spacing ratio $D / \Delta H$ seems to exist for the two geogrid reinforcement used in this paper.

\section{ACKNOWLEDGEMENTS}

The authors would like to thank Prof. F. Tatsuoka and Mr. T. Satoh of the University of Tokyo for allowing them to use the experimental apparatus reported in this paper. Gratitude is also extended to Mr. M. Akatsu and Mr. M. Hatano for their support in conducting the test series and their comments on this paper.

\section{NOTATION}

$e_{\max }:$ maximum void ratio

$e_{\text {min }}$ : minimum void ratio

$D$ : depth of the sample

$D_{50}$ : maximum grain size in smallest $50 \%$ of sample

$D_{\text {max }}$ : maximum grain size of sample

$D_{r}:$ relative density

$G_{s}:$ specific gravity

$\Delta H$ : spacing of the samples

$U_{c}$ : coefficient of uniformity

$U_{c}^{\prime}$ : coefficient of curvature

$\alpha, \beta$ : constants

$\varepsilon_{1}:$ axial strain

$\varepsilon_{3}:$ lateral strain

$\varepsilon_{V}: \quad$ volumetric strain

$\phi_{f}$ : apparent angle of internal friction at failure

$\sigma_{1}:$ axial stress

$\sigma_{2}$ : lateral stress normal to plane strain axis (in and out of the plane stress)

$\sigma_{3}$ : lateral stress parallel to plane strain axis

$\left(\sigma_{1} / \sigma_{3}\right)_{f}$ : axial to lateral stress ratio at failure

\section{REFERENCES}

1) Akagi, T., Higuchi, T. and Chida, S. (1994): "Engineering properties of five major geogrids in Japan," Proc. Int. Conf. Geotextiles, Geomembranes and Related Products, pp. 401-404.

2) Bouazza, A. and Wei, M. J. (1992): "Large scale pull-out tests on polypropylene reinforcing straps embedded in various fills," Earth Reinforcement Practice, Ochiai, Hayashi and Otani (eds), Balkema, Rotterdam.

3) Cancelli, A., Rimoldi, P. and Togni, S. (1992): "'Frictional characteristics of geogrids by means of direct shear and pull-out tests," Earth Reinforcement Practice, Ochiai, Hayashi and Otani (eds), Balkema, Rotterdam.

4) Hamada, H., Tatsuoka, F., Kanefuji, H., Kubota, T. and Satoh. T. (1983): "Plane strain compression tests on reinforced sand," Proc. 18th Japan National Conf. Soil Mech. Found. Mech., pp. 1201-1204 (in Japanese).

5) Japanese Society of Soil Mech. Found. Eng. (1988): “Geotechnical Engineering Library 29: Construction methods of reinforced earth," pp. 27-71 (in Japananese).

6) Kutara, K., Aoyama, N., Takauchi, T. and Yasunaga, H. (1987): "Large triaxial compression test of sand reinforced with geotextile," Proc. 2nd Japan Geotextile Symp., pp. 56-62 (in Japanese).

7) Kutara, K., Miki, H., Hirai, T. and Kamasaki, H. (1991): “Behavior of reinforced earth by FRP geotextile in large scale triaxial com- 
pression test," Proc. 26th Japan National Conf. Soil. Mech. Found. Eng., pp. 2185-2188 (in Japanese).

8) Mitachi, T., Yamamoto, Y. and Muraki, S. (1992): "Estimation of in-soil deformation behavior of geogrid under pull-out loading," Earth Reinforcement Practice, Ochiai, Hayashi and Otani (eds), Balkema, Rotterdam.

9) Moroto, N. (1992): "Triaxial compression test for reinforced sand with a flexible tension member," Earth Reinforcement Practice, Ochiai, Hayashi and Otani (eds), Balkema, Rotterdam.

10) Nishimura, J. and Takaoka, K. (1988): "The study on the confining effect geogrid," Proc. 3rd Japan Geotextile Symp., pp. 23-26 (in Japanese).

11) Ochiai, H., Hayashi, S., Otani, J. and Hirai, T. (1992): "Evalution of pull-out resistance of geogrid reinforced soils," Earth Reinforcement Practice, Ochiai, Hayashi and Otani (eds), Balkema, Rotterdam.

12) Yang, Z. (1972): "Strength and deformation characteristics of reinforced sand," Ph.D. Thesis, University of California, Los Angeles, p. 236. 